\title{
1 Momentary liquefaction of porous seabed under vertical \\ 2 seismic action
}

3 Weiyun Chen ${ }^{\mathrm{a}}$, Dongsheng Jeng ${ }^{\mathrm{b}}$, Guoxing Chen ${ }^{\mathrm{a}}$, Hongyi Zhao ${ }^{\mathrm{c}^{*}}$, Rui He $\mathrm{H}^{\mathrm{c}}$,

4 Hongmei $\mathrm{Gao}^{\mathrm{a}}$

$5 \quad{ }^{a}$ Institute of Geotechnical Engineering, Nanjing Tech University, Nanjing 210009, China

6 b Griffith School of Engineering, Griffith University Gold Coast Campus, Queensland QLD 4222,

7 Australia

$8{ }^{c}$ College of Harbor, Coastal and Offshore Engineering, Hohai University, Nanjing 210098,

9 China

\section{Abstract}

The evaluation of potential liquefaction is an important part in the design of marine structures and offshore installations. However, the liquefaction phenomenon of porous seabed under the action of strong earthquake is traditionally been ignored. This paper aims to explore the momentary liquefaction mechanism of porous seabed through the newly analytical solutions of seabed response induced by vertical seismic excitation. Based on the boundary conditions at the surface and bottom of the seabed, the induced displacements and pore pressure in the sediment are rigorously derived as a function of seawater depth, seabed parameters and seismic characteristics of bedrock. A criterion of earthquake liquefaction in the seabed is developed, employing the concept of induced excess pore pressure. The representative cohesionless marine soils with different properties are selected in the parametric analysis. The results show that the liquefaction of seabed could be influenced by seawater parameters, seabed parameters and earthquake ground motion parameters. The significant finding is that current understanding that the vertical motion effect on soil liquefaction is negligible may not always hold true.

Keywords: Momentary liquefaction; Porous seabed; Vertical earthquake; Partial saturation; Pore pressure 
2 Liquefaction is a process that material transforms from initially solid state into liquid state.

3 Theoretical analysis of this phenomenon has for decades been a great challenge in geomechanics,

4 earthquake engineering as well as marine engineering [1-3]. In the marine environment,

5 liquefaction also plays an important role around and beneath offshore structures, as it often occurs

6 in saturated or nearly saturated granular materials, like noncohesive seabed soils. The liquefaction

7 of seabed may lead to destructive consequences, such as floating up of pipelines in the seabed,

8 tilting of caissons and deformation of undersea tunnel. Hence the evaluation for liquefaction

9 behavior of seabed is of practical significance in the design and construction of marine structures

10 and offshore installations.

11 Massive liquefaction of the seabed happens as a result of pore pressure change and the corresponding degradation of the soil's macroscopic properties. Generally, the pressure change of the water trapped in soil skeleton pore comes from external excitation such as ocean-waves and earthquake. The issue of ocean-waves induced seabed response and instability has attracted great attention from geotechnical and coastal engineers since 1970s [4-7]. The water waves propagating on the ocean could create significant dynamic wave pressure on the seabed surface and cyclic pore pressure in marine sediments [8]. Owning to the phase lags and damping of the dynamic wave pressure, the excess pore pressure is produced from the difference between the wave pressure on the seabed surface and pore pressure in the sediment. When the value of the excess pore pressure directly exceeds a certain mean level, the vertical effective stress vanishes and the momentary liquefaction may happen in the seabed [9]. Other mechanism is wave-induced residual liquefaction, which is due to the build-up of excess pore pressure caused by the volumetric compaction under cyclic wave loading [10].

24 On the other hand, apart from the ocean-waves, catastrophic damage to offshore structures has 25 also been recorded in the past earthquakes [11,12]. However, the analytical and numerical investigations on seismic dynamics of porous seabed are still limited to date [13-16]. The behaviors of the loads from ocean-waves and earthquake are both periodic but have notably different characteristics (see Table 1). In general, seismic waves propagate in the form of shear and compressional waves, which depends on the vibrating direction of the substrate bedrock. The 
1 behavior of external cyclic shearing of saturated soil have been confirmed experimentally by 2 dozens of independent laboratories [17-19]. Most of these tests have simulated the liquefaction triggered by shear waves, revealing that the build-up of excess pore pressure in the response could reduce the effective stresses and subsequently the shearing resistance of the soil skeleton. This mechanism results from the 'residual' nature of the excess pore pressure, which accumulates gradually after a certain number of wave cycles. This phenomenon is similar to the residual liquefaction induced by ocean waves, caused by the build-up of the excess pore pressure [10].

The other potential liquefaction induced by compressional waves, however, was rarely regarded in geotechnical earthquake engineering, especially through theoretical analysis. As discussed by Yang [20], the understanding that the effect of vertical motion on liquefaction is negligible may not always hold true and the effect is dependent on the saturation condition. The purpose of this study is to explore the momentary liquefaction mechanism in the marine porous sediment which is subjected to vertical seismic action. A new analytical solution for the induced displacements and pore pressure in the seabed are mathematically obtained based on the poro-elastic theory. The effects of several pertinent parameters on the earthquake-induced distribution of liquefied area are then discussed in detail.

\section{Governing equations and general solutions}

\subsection{Governing equations for the seabed}

In this study, the marine sediment is considered as a mixture consisting of solid skeletal frame, liquid phase, and gas phase. Some basic assumptions are introduced to derive the analytical solutions for the phenomenon described, such as:

- the partially saturated sediment is homogeneous and hydraulically isotropic material;

- the seabed is elastic, porous, horizontal and of finite thickness;

- both the soil skeleton and the pore fluids are compressible;

- the soil skeleton generally obeys Hooke's law, implying linear, reversible and non-retarded mechanical properties;

- the flow in the porous seabed is governed by Darcy's law.

The governing equations for the dynamic response of porous seabed is developed in this section, 
1 following the formulation in Zienkiewicz et al. [21] and Ulker and Rahman [22]. The equilibrium

2 equation for the overall porous medium can be written as

$$
\sigma_{i j, j}+\rho g_{i}-\rho \ddot{u}_{i}-\rho_{f} \ddot{\bar{w}}_{i}=0
$$

where $\sigma_{i j}$ is total stress, $g_{i}$ is the gravitational acceleration, $\rho$ denotes the total density of porous medium, $\rho=(1-n) \rho_{s}+n \rho_{f}$, $\rho_{s}$ is the density of the solid skeleton, $n$ is the soil porosity; $\rho_{f}$ is the fluid density, $u_{i}$ represents the displacement of soil skeleton, $\bar{w}$ is the average pore fluid displacement relative to solid frame and is defined as

$$
\bar{w}=n\left(w_{f}-u\right)
$$

where $w_{f}$ is the total displacement of the pore fluid.

The equilibrium of fluid can be written as

$$
-p_{, j}+\rho_{f} g_{i}-\rho_{f} \ddot{u}_{i}-\frac{\rho_{f}}{n} \ddot{\bar{w}}_{i}-\frac{\rho_{f} g_{i}}{k_{f}} \dot{\bar{w}}_{i}=0
$$

where $p$ is the pore fluid pressure, $k_{f}$ is the hydraulically isotropic permeability of porous seabed.

The mass conservation equation can be expressed as

$$
\dot{u}_{i, i}+\dot{\bar{w}}_{i, i}=-n \beta \dot{p}
$$

where $\beta$ is the compressibility of pore fluid defined as $[23,24]$

$$
\beta=\frac{1}{K_{w}}+\frac{1-S_{r}}{p_{w 0}}
$$

where $K_{w}$ is the true bulk modulus of water, $S_{r}$ is the saturation degree, $p_{w 0}$ is the absolute water pressure, i.e., $p_{w o}=\rho_{f} g d, d$ is the water depth.

The constitutive relationship between effective stress $\sigma_{i j}^{\prime}$ and pore fluid pressure $p$ can be represented by $[21,22]$

$$
\sigma_{i j}=\sigma_{i j}^{\prime}-\delta_{i j} p
$$

where $\delta_{i j}$ is Kronecker delta; Note that total stress $\sigma_{i j}$ and effective stress $\sigma_{i j}^{\prime}$ are considered to be positive; $p$ is pore pressure and tension is taken a sositive in this equation.

The strain $\varepsilon_{i j}$ is defined as: 


$$
\varepsilon_{i j}=\frac{1}{2}\left(u_{i, j}+u_{j, i}\right)
$$

2 where $u_{i, j}$ and $u_{j, i}$ denote the derivatives of the solid displacement with respect to spatial 3 coordinates.

4 The constitutive relations of the skeleton can be defined incrementally in terms of effective 5 stress changes as

6

$$
\Delta \sigma_{i j}^{\prime}=D_{i j k l} \Delta \varepsilon_{k l}
$$

where $D_{i j k l}$ is the tangent coefficient matrix and $\Delta \varepsilon_{k l}$ is the strain change from initial state. In plane strain, the effective stress change can be rewritten as

$$
\Delta \sigma_{i j}^{\prime}=\lambda \Delta \varepsilon_{k k} \delta_{i j}+2 \mu \Delta \varepsilon_{i j}
$$

where $\lambda$ and $\mu$ are Lame's parameters, $\Delta \varepsilon_{k k}$ is volumetric strain change. $\mu$ is also called shear modulus and $\lambda=2 \mu v /(1-2 v)$ with the Poisson's ratio $v$.

Herein, a porous sediment layer lying on the bedrock is considered, as depicted in Fig. 1. The depth of upper seawater is $d$ and the thickness of poroelastic seabed is $L$. The $z$-direction is measured as positive upwards from the bedrock surface, while $x$-direction is parallel to the horizontal seabed surface. The steady-state displacement of seismic excitation is specified vertically on the impermeable bedrock surface. Accordingly, the variables $\tilde{u}$ and $\tilde{w}$ are adopted to represent the earthquake-induced soil skeleton displacement and average fluid relative displacement in $z$-direction, respectively. In this linear elastic system, the Eqs. (1)-(3) in absence of body force can reduce to:

$$
\begin{aligned}
& \left(\lambda+2 \mu+\frac{1}{n \beta}\right) \frac{\partial^{2} \tilde{u}}{\partial z^{2}}+\frac{1}{n \beta} \frac{\partial^{2} \tilde{w}}{\partial z^{2}}-\rho \frac{\partial^{2} \tilde{u}}{\partial t^{2}}-\rho_{f} \frac{\partial^{2} \tilde{w}}{\partial t^{2}}=0 \\
& \frac{1}{n \beta}\left(\frac{\partial^{2} \tilde{u}}{\partial z^{2}}+\frac{\partial^{2} \tilde{w}}{\partial z^{2}}\right)-\frac{\rho_{f} g}{k_{f}} \frac{\partial \tilde{w}}{\partial t}-\rho_{f} \frac{\partial^{2} \tilde{u}}{\partial t^{2}}-\frac{\rho_{f}}{n} \frac{\partial^{2} \tilde{w}}{\partial t^{2}}=0
\end{aligned}
$$

Combining Eqs. (10) and (11), the governing equation for the soil skeleton displacement can be expressed as a four-order equation

$$
\frac{\partial^{4} \tilde{u}}{\partial t^{4}}+a_{1} \frac{\partial^{3} \tilde{u}}{\partial t^{3}}+a_{2} \frac{\partial^{4} \tilde{u}}{\partial t^{2} \partial z^{2}}+a_{3} \frac{\partial^{3} \tilde{u}}{\partial t \partial z^{2}}+a_{4} \frac{\partial^{4} \tilde{u}}{\partial z^{4}}=0
$$

with 


$$
\begin{array}{ll}
a_{1}=-\frac{n \rho g}{k_{f}\left(n \rho_{f}-\rho\right)} & a_{2}=\frac{n \rho+\rho_{f}[(\lambda+2 \mu) n \beta+1-2 n]}{\rho_{f} n \beta\left(n \rho_{f}-\rho\right)} \\
a_{3}=\frac{g[(\lambda+2 \mu) n \beta+1]}{\beta k_{f}\left(n \rho_{f}-\rho\right)} & a_{4}=-\frac{\lambda+2 \mu}{\beta \rho_{f}\left(n \rho_{f}-\rho\right)}
\end{array}
$$

\subsection{Analytical solutions for response variables}

4 Since the analysis is restricted to a linear periodic response, it is expedient to employ complex variables and then the earthquake-induced displacements are assumed as

$$
\left\{\begin{array}{l}
\tilde{u} \\
\tilde{w}
\end{array}\right\}=\left\{\begin{array}{l}
u_{0} \\
w_{0}
\end{array}\right\} \exp [\mathrm{i}(\omega t-z k)]
$$

where $u_{0}$ and $w_{0}$ represent the corresponding amplitudes, $\mathrm{i}$ is the root of $-1, t$ denotes time, $\omega$ is the angular frequency, $k$ is a complex number. Then Eq. (12) becomes

$$
a_{4} k^{4}+\left(a_{2} \omega^{2}-\mathrm{i} a_{3} \omega\right) k^{2}+\omega^{4}-\mathrm{i} a_{1} \omega^{3}=0
$$

Four different roots can be solved for Eq. (14) as $\pm k_{p 1}$ and $\pm k_{p 2}$. In soil dynamics, $k_{p 1}$ and $k_{p 2}$ represent the wave numbers for the fast and slow compressional waves in the saturated soils [25]. Then, the general analytical solutions for solid displacement $\tilde{u}$ and average relative fluid displacement $\tilde{w}$ can be represented as (for brevity the steady-state factor exp(i $\omega t)$ is omitted)

$$
\begin{gathered}
\tilde{u}=b_{1} \exp \left(-\mathrm{i} k_{p 1} z\right)+b_{2} \exp \left(\mathrm{i} k_{p 1} z\right)+b_{3} \exp \left(-\mathrm{i} k_{p 2} z\right)+b_{4} \exp \left(\mathrm{i} k_{p 2} z\right) \\
\tilde{w}=b_{1} \eta_{1} \exp \left(-\mathrm{i} k_{p 1} z\right)+b_{2} \eta_{2} \exp \left(\mathrm{i} k_{p 1} z\right)+b_{3} \eta_{3} \exp \left(-\mathrm{i} k_{p 2} z\right)+b_{4} \eta_{4} \exp \left(\mathrm{i} k_{p 2} z\right)
\end{gathered}
$$

with

$$
\begin{aligned}
& \eta_{1}=\eta_{2}=\frac{\left(\lambda+2 \mu+\frac{1}{n \beta}\right) k_{p 1}^{2}-\omega^{2} \rho}{\omega^{2} \rho_{f}-\frac{1}{n \beta} k_{p 1}^{2}} \\
& \eta_{3}=\eta_{4}=\frac{\left(\lambda+2 \mu+\frac{1}{n \beta}\right) k_{p 2}^{2}-\omega^{2} \rho}{\omega^{2} \rho_{f}-\frac{1}{n \beta} k_{p 2}^{2}}
\end{aligned}
$$

For the homogeneous seabed shown in Fig. 1, the evaluation of coefficients $b_{j}(j=1-4)$ in Eqs. (15) - (16) requires appropriate boundary conditions. Firstly, at seabed surface $(z=L)$, the 
seismically induced pore pressure $\tilde{p}$ equals to the induced dynamic pressure of the overlying seawater $\tilde{p}_{w}$, while the induced vertical effective stress $\tilde{\sigma}_{z z}^{\prime}$ disappears. The continuity of fluid volume should also be considered to describe the induced displacements of pore fluid and upper seawater. Thus, these surface boundary conditions are given as

$$
-\tilde{p}=\tilde{p}_{w}, \quad \tilde{\sigma}_{z z}^{\prime}=0, \quad \tilde{w}_{u}=(1-n) \tilde{u}+n \tilde{w}_{f}=\tilde{u}+\tilde{w} \quad \text { at } \quad z=L
$$

where $\tilde{w}_{u}$ is the induced displacement of seawater above the seabed surface. $\tilde{w}_{f}$ is the induced displacement of pore fluid in the soils. $\tilde{p}_{w}$ is the dynamic seawater pressure induced by the vibration of seabed, the negative sign is due to the definition that pore pressure is taken as negative in Eq. (6). The dynamic seawater pressure takes the form as [26, 27]

$$
\tilde{p}_{w}=\rho_{f} d \ddot{\tilde{w}}_{u}
$$

Secondly, no vertical relative flow occurs at the horizontal seabed bottom where the vertical displacement excitation is acting at, i.e.,

$$
\tilde{u}=u_{0} \exp (\mathrm{i} \omega t), \tilde{w}=0 \quad \text { at } z=0
$$

Enforcing the above boundary conditions at both the seabed surface and bottom, the following matrix form can be obtained

$$
[M]\left[b_{1}, b_{2}, b_{3}, b_{4}\right]^{T}=[N]
$$

The explicit expressions of the elements $m_{i j}$ of $[M]$ are given as follows

$$
\begin{aligned}
& m_{11}=m_{12}=m_{13}=m_{14}=1 \\
& m_{21}=\eta_{1} \quad m_{22}=\eta_{2} \quad m_{23}=\eta_{3} \quad m_{24}=\eta_{4} \\
& m_{31}=-k_{p 1} \exp \left(-\mathrm{i} k_{p 1} L\right) \\
& m_{32}=k_{p 1} \exp \left(\mathrm{i} k_{p 1} L\right) \\
& m_{33}=-k_{p 2} \exp \left(-\mathrm{i} k_{p 2} L\right) \\
& m_{34}=k_{p 2} \exp \left(\mathrm{i} k_{p 2} L\right) \\
& m_{41}=\left[n \beta \rho_{f} d \omega^{2}-\mathrm{i}\left(1+\eta_{1}\right) k_{p 1}\right] \exp \left(-\mathrm{i} k_{p 1} L\right) \\
& m_{42}=\left[n \beta \rho_{f} d \omega^{2}+\mathrm{i}\left(1+\eta_{2}\right) k_{p 1}\right] \exp \left(\mathrm{i} k_{p 1} L\right) \\
& m_{43}=\left[\begin{array}{ll}
n \beta \rho_{f} & d \omega^{2}-\mathrm{i}\left(1+\eta_{3}\right) k_{p 2}
\end{array}\right] \exp \left(-\mathrm{i} k_{p 2} L\right) \\
& m_{44}=\left[n \beta \rho_{f} d \omega^{2}+\mathrm{i}\left(1+\eta_{4}\right) k_{p 2}\right] \exp \left(\mathrm{i} k_{p 2} L\right)
\end{aligned}
$$

The elements in $[N]$ are given by 
Then the undetermined coefficients $b_{j}(j=1-4)$ in Eqs. (15)-(16) can be solved. Based on the

constitutive relations, the earthquake-induced pore pressure generated in the seabed can be further expressed as

$$
\tilde{p}=\frac{\mathrm{i}}{n \beta}\left[\begin{array}{l}
b_{1}\left(1+\eta_{1}\right) k_{p 1} \exp \left(-\mathrm{i} k_{p 1} z\right)-b_{2}\left(1+\eta_{2}\right) k_{p 1} \exp \left(\mathrm{i} k_{p 1} z\right) \\
+b_{3}\left(1+\eta_{3}\right) k_{p 2} \exp \left(-\mathrm{i} k_{p 2} z\right)-b_{4}\left(1+\eta_{4}\right) k_{p 2} \exp \left(\mathrm{i} k_{p 2} z\right)
\end{array}\right]
$$

\section{Characteristics of seismic-induced response in porous seabed}

Under the load of earthquake, the induced displacements and pore pressure in seabed always play an important role around and beneath the offshore structures such as submarine pipeline and tunnel. Okusa [28] demonstrated that saturation degree was an influential factor in the evaluation of seabed response under the action of ocean-waves. Based on the obtained analytical solutions, this section aims to investigate the effects of soil permeability and earthquake frequency on the seismic-induced displacements and pore pressure in the porous seabed with full saturation or partly saturation. To have a basic understanding of the response characteristics, we discuss three types of non-cohesive marine soils which are associated with distinct values of permeability. For example, $k_{f}=10^{-4} \mathrm{~m} / \mathrm{s}$ is assumed for fine sand, $k_{f}=10^{-3} \mathrm{~m} / \mathrm{s}$ for medium sand and $k_{f}=10^{-2} \mathrm{~m} / \mathrm{s}$ for coarse sand [29]. In the following calculation, the density of solid grain $\rho_{s}=2650 \mathrm{~kg} / \mathrm{m}^{3}$, the density of water $\rho_{f}=1030 \mathrm{~kg} / \mathrm{m}^{3}$ and the bulk modulus of water $K_{w}=2.0 \mathrm{GPa}$.

First, the motion amplification factor at the seabed surface without seawater (i.e., $d=0 \mathrm{~m}$ ) is compared with the previous method [28], as shown in Fig. 2. Here the amplification factor is defined as the ratio of the amplitude of solid displacement at any depth to that at the bottom of seabed. The main parameters of the comparison are: $n=0.37, k_{f}=0.001 \mathrm{~m} / \mathrm{s}, \mu=65 \mathrm{MPa}, L=15$ $\mathrm{m}, d=0 \mathrm{~m}$. It is indicated from Fig. 2 that the present results agree overall with Yang and Sato [30], especially for the fully saturated seabed $\left(S_{r}=100 \%\right)$ within the common frequency range of undersea earthquake. When the compressibility of solid grains is neglected, the governing equations in Yang and Sato [30] are identical with eqs. (10) and (11). The discrepancy between the present study and Yang and Sato [30] may come from different derivation process of solutions 
and the compressibility of grains which is neglected here.

In Figs. 3 and 4, the vertical distribution of maximum amplitudes of earthquake-induced solid displacement $|\tilde{u}|$, relative fluid displacement $|\tilde{w}|$ and pore pressure $|\tilde{p}|$ versus relative soil depth $(z / L)$ is presented. The influence of soil permeability and excitation frequency is respectively illustrated. The solid displacement and relative fluid displacement are non-dimensionalized with respect to the displacement amplitude at the seabed bottom while the pore pressure is normalized by the absolute hydrostatic water pressure at the seabed surface. The situations of both full saturation $\left(S_{r}\right.$ $=100 \%)$ and part saturation $\left(S_{r}=99 \%\right)$ are considered. It should be noted that the partial saturation of $99 \%$ used here is just a research hypothesis that may possibly be found in the real seabed soil [31]. Significant difference is noticed between the seismically induced response in partial and full saturations. It may be related with the fact that the compressibility of pore fluid $\beta$ drops rapidly when the saturation degree is close to $100 \%$, as depicted in Fig. 5.

In Fig. 3(a), compared with the results of full saturation, the induced solid displacement $|\tilde{u}|$ in the case of incomplete saturation is usually much greater. Thus it should be noted that a saturated model will always underestimate the motion amplification in the seabed. Compared with relative fluid displacement $|\tilde{w}|$ in Fig. 3(b), the induced solid displacement $|\tilde{u}|$ in Fig. 3(a) is less sensitive to the change of soil permeability in both the cases of full saturation and part saturation. This finding is due to the fact that the motion of fluid flowing in the pore of seabed is closely related to the permeability of the soil. Since the higher the permeability is, the resistance between the solid skeleton and pore fluid is weaker, the relative fluid flow becomes larger. As illustrated in Fig. 3(b), the induced relative fluid displacement increases with the increasing permeability. Moreover, the fluid displacement grows rapidly near the seabed surface while drop quickly near the seabed bottom. This can be explained by the open-pore boundary between seawater and seabed surface and impermeability of seabed bottom. The increasing trend of $|\tilde{w}|$ near the surface of incompletely saturated seabed is shown to be more obvious and this trend also increases with the decrease of permeability. As shown in Fig. 3(c), greater pore pressure is generated in the nearly saturated case. When the soil permeability is relatively low, such as $k_{f} \leq 10^{-3} \mathrm{~m} / \mathrm{s}$, the influence of permeability on the induced displacement and pore pressure in most part of the seabed is insignificant. 
In Fig. 4(a), the vertical displacement changes more significant from the seabed bottom to its upper surface with the increasing of frequency. This finding is certainly reasonable from an intuitive point of view, since the case of sufficiently low frequency will approach to the quasi-static state and the whole seabed will have the same displacement. Similarly, as depicted in Fig. 4(b), the induced relative fluid displacement increases with the increasing frequency. In most depth of seabed, greater pore pressure is induced under the earthquake of higher frequency when the frequency is higher than $2 \mathrm{~Hz}$, as shown in Fig. 4(c).

\section{Momentary liquefaction of seabed}

\subsection{Criteria of momentary liquefaction}

To apply an analysis on seismic-induced liquefaction in porous seabed, Fig. 6 shows the schematic drawings of vertical distribution of the (pore) water pressure and effective vertical stress. In Fig. 6(a), the solid lines $a$ and $b$ indicate vertical distributions for the maximum and minimum (pore) water pressure beneath the downward and upward earthquake peaks, respectively. In Fig. 6(b), lines $a$ and $b$ represent the corresponding vertical effective stresses in the seabed under opposite earthquake peaks. In general, the excess pore pressure, also called the excess hydrostatic pressure, is defined as the excess component of pressure beyond the hydrostatic pressure. Because the induced dynamic seawater pressure on the seabed surface varies so quickly that the it is not thoroughly propagated into the deposit. Thus the excess pore pressure $p_{e}(z, t)$, as shown in Fig. 6(a), is represented by the difference between the water pressure change imposed on the seabed surface and the induced pore pressure change from the initial hydrostatic state [9]:

$$
p_{e}(z, t)=\tilde{p}(z, t)-\tilde{p}(L, t)
$$

where $\tilde{p}(z, t)$ denotes the seismically induced pressure at a certain depth in the seabed, i.e., the change from hydrostatic pressure to lines $a$ and $b$ in Fig. 6(a). $\tilde{p}(L, t)$ represents the hydrostatic pressure change in the seabed under the action of earthquake peaks, depicted by the difference between the hydrostatic pressure line and dash lines in Fig. 6(a). The dash lines in Fig. 6(a) depict the distributions of hydrostatic pressures when the seabed surface is under the induced pressures of seawater. In addition, since the excess pore pressure is transient in nature, the effective stress also varies in accordance with the change of the excess pore pressure in the seabed. Zen and 
1 Yamazaki [9] have shown that the magnitude of the change in vertical effective stress is identical

2 with the induced excess pore pressure in the seabed. And it has been conceived that the soil will be

3 liquefied when the vertical effective stress instantaneous vanishes, thus losing its strength to bear

4 any load, and consequently causing seabed instability. As depicted in Fig. 6(b), the criterion for

5 the earthquake-induced liquefaction can described as

$$
\gamma^{\prime}(L-z)-[\tilde{p}(z, t)-\tilde{p}(L, t)] \leq 0
$$

where $\gamma^{\prime}$ denotes the effective unit weight of soil. This inequality implies that liquefaction in a seabed may occur if the induced excess pore pressure becomes greater than the overburden soil pressure. The liquefaction criterion employing the excess pore pressure in Eq. (27) could be an applicable means [6]. Consequently, the potential depth range of momentarily liquefied area in Fig. 6(b) is $d_{t} \leq z \leq L$.

\subsection{Depth of liquefied seabed area}

The analytical solutions for the vertically earthquake-induced response, which are given in Section 1, contain three main groups of parameters as follows: seawater parameters such as water depth $d$; seabed parameters including seabed thickness $L$, hydraulic permeability $k_{f}$, porosity $n$, Poisson's ratio $v$, saturation degree $S_{r}$, fluid compressibility $\beta$, shear modulus $\mu$; and earthquake ground motion parameters represented by excitation frequency $f$ and displacement amplitude $u_{0}$. In these parameters, the fluid compressibility $\beta$ depends on the water depth $d$ and saturation degree $S_{r}$, as illustrated in Fig. 5. The effects of permeability $k_{f}$ can be considered as a main factor to distinguish different marine soil types. In the following parametric analysis, the porosity $n$ and Poisson's ratio $v$ of the marine soils are assumed to be constants and the degree of saturation is considered to vary from $99 \%$ to $100 \%$.

The seawater depth does not only influence the pore fluid compressibility $\beta$ through Eq. (5) but also determines the dynamic seawater pressure on the seabed surface as described in Eq. (20). Therefore, the depth of the seawater above the seabed is a dominant factor for the seismically induced response of porous seabed. Fig. 7 depicts the influence of seawater depth on the variation of liquefaction depth with saturation degree. The depths of seawater are selected to be $2.5 \mathrm{~m}, 5 \mathrm{~m}$, $10 \mathrm{~m}$ and $20 \mathrm{~m}$, respectively. It is shown that the liquefaction depth decreases with the increasing of saturation degree in the nearly saturated seabed. This is due to the fact that the induced pore 
1 pressure will increase when the saturation degree approaches fully saturated state, which are

2 explained in Eq. (25) and Fig. 5. As shown in Fig. 7, the liquefaction depth also increases with the depth of seawater. This is because the dynamic water pressure at the surface of seabed is proportionate to the water depth. Moreover, in the case of complete saturation, the depth of liquefied area is found to be in proportion to the water depth.

Fig. 8 shows the influence of seabed thickness on the variation of liquefaction depth with saturation degree. The liquefaction depth increases with the thickness of seabed when the porous seabed is not completely saturated. However, it should be noted that the depth of liquefied area almost remains constant (about $7.5 \mathrm{~m}$ ) when the seabed is fully saturated. Thus the liquefaction depth of saturated porous seabed is independent of seabed thickness.

In Fig. 9, the influence of soil permeability on the liquefaction depth is insignificant. Because larger pore pressure will be generated in the earthquake with higher frequency or larger excitation displacement, the liquefaction depth also increases with the earthquake frequency and displacement amplitude, as shown in Figs. 10 and 11. The shear modulus also has marked effect on the liquefaction of the cohesionless soil seabed. As illustrated in Fig. 12, the liquefaction depth increases with the shear modulus when the porous seabed is not completely saturated. However, it is worthwhile to note that the depth of liquefied area remains at about $7.5 \mathrm{~m}$ when the seabed is fully saturated.

\section{Conclusions}

The aim of this paper is to analyze the momentary liquefaction phenomenon of porous seabed under the action of vertical earthquake, which has traditionally been ignored in geotechnical earthquake engineering. It should be noted that the momentary mechanism discussed here adopts poro-elastic theory, which is different from the residual one based on elasto-plastic analysis. Therefore, the conclusions drawn in this paper are limited to the momentary liquefaction instead of the residual one caused by the build-up of pore pressure under cyclic shearing. The analytical solutions of the induced displacements and pore pressure are mathematically derived as a function of seawater depth, soil properties, seabed thickness, excitation frequency and amplitude. The significant finding is that current understanding that the vertical motion effect on soil liquefaction is negligible may not always hold true and the following conclusions could be summarized: 
(1) Even if the degree of saturation is only slightly below full saturation, its impact on the seismically induced response such as displacement and pore pressure is significant.

(2) The earthquake-induced pore pressure in the seabed reaches the maximum near the middle position.

(3) Based on the proposed criterion for the momentary earthquake liquefaction in the seabed, the liquefaction of the cohesionless soil seabed happens from the seabed surface.

(4) The liquefaction of seabed is influenced by seawater parameters, seabed parameters and earthquake ground motion parameters.

(5) The saturation degree of soil, earthquake frequency and displacement amplitude of excitation are major influencing factors determining the depth of liquefied seabed.

(6) When the seabed is fully saturated, the liquefaction depth of seabed is found to be proportionate to seawater depth while independent of seabed thicknesses and shear modulus.

(7) The liquefaction occurs from the shallow layer of seabed where most of construction of marine structures are installed, which should merit our attention in practical engineering.

\section{Acknowledgements}

The authors would like to acknowledge the financial support provided by the National Natural Science Foundation of China (No. 41502285, 41402245, 51509082), Natural Science Foundation of Jiangsu Province (No. BK20150952). China Scholarship Council is also acknowledged by the first author for supporting him during his visiting in the Griffith University.

\section{References}

[1] Ishihara K. Soil behaviour in earthquake geotechnics, Clarendon Press, Oxford, 1996.

[2] Papatheodorou G, Ferentinos G. Submarine and coastal sediment failure triggered by the 1995, Ms = 6.1 R Aegion earthquake, Gulf of Corinth, Greece. Mar Geol 1997; 137(3): 287-304.

[3] Sawicki A, Świdziński W. Simple mathematical model for assessment of seismic-induced liquefaction of soils. J Waterw Port Coast Ocean Eng ASCE 2007; 133(1): 50-54.

[4] Yamamoto T, Koning HL, Sellmeijer H, Van Hijum EP. On the response of a poro-elastic bed to water waves. J Fluid Mech 1978; 87(01): 193-206.

[5] Mei CC, Foda MA. Wave-induced responses in a fluid-filled poro-elastic solid with a free surface-a boundary layer theory. Geophys J Int 1981; 66(3): 597-631. 
1 [6] Jeng DS. Wave-induced seabed instability in front of a breakwater. Ocean Eng 1997; 24(10): 887-917.

[7] Liu Z, Jeng DS, Chan AHC, Luan M. Wave-induced progressive liquefaction in a poro-elastoplastic seabed: a two-layered model. Int J Numer Anal Met 2009; 33(5): 591-610.

[8] Jeng DS, Rahman, MS. Effective stresses in a porous seabed of finite thickness: Inertia effects. Can Geotech J 2000; 37(6): 1383-1392.

[9] Zen K, Yamazaki H. Mechanism of wave-induced liquefaction and densification in seabed. Soils Found 1990; 30(4): 90-104.

[10] Jeng DS, Zhao HY. Two-dimensional model for accumulation of pore pressure in marine sediments. J Waterw Port Coast Ocean Eng ASCE 2014; 141(3): 04014042.

[11] Greene H G, Gardner-Taggart J, Ledbetter MT, Barminski R, Chase TE, Hicks KR, Baxter C. Offshore and onshore liquefaction at Moss Landing spit, central California-Result of the October 17, 1989, Loma Prieta earthquake. Geology 1991; 19(9): 945-949.

[12] Sumer BM, Kaya A, Hansen NEO. Impact of liquefaction on coastal structures in the 1999 Kocaeli, Turkey earthquake. Proceedings of the international offshore and polar engineering conference 2002; 12: 504-511.

[13] Ye J. Seismic response of poro-elastic seabed and composite breakwater under strong earthquake loading. Bull. Earthquake Engng 2012; 10(5): 1609-1633.

[14] Ye J, Wang G. Seismic dynamics of offshore breakwater on liquefiable seabed foundation. Soil Dyn Earthq Eng 2015; 76: 86-99.

[15] Rodríguez-Castellanos A, Martínez-Calzada V, Rodríguez-Sánchez JE, Orozco-Del-Castillo M, Carbajal-Romero M. Induced water pressure profiles due to seismic motions. Appl Ocean Res 2014; 47: 9-16.

[16] Ávila-Carrera R, Flores-Guzmán N, Olivera-Villaseñor E, Rodríguez-Castellanos A, Rodríguez-Sánchez JE. Seismic amplifications from offshore to shore. Appl Ocean Res 2015; 53: 200-207.

[17] Zhou YG, Chen YM. Influence of seismic cyclic loading history on small strain shear modulus of saturated sands. Soil Dyn Earthq Eng 2005, 25(5):341-353.

[18] Kagawa T, Sato M, Minowa C, Abe A, Tazoh T. Centrifuge simulations of large-scale shaking table tests: case studies. J Geotech Eng ASCE 2004; 130(7): 663-672.

[19] El Takch A, Sadrekarimi A, El Naggar H. Cyclic resistance and liquefaction behavior of silt and sandy silt soils. Soil Dyn Earthq Eng 2016; 83: 98-109. 
1 [20] Yang J. Reappraisal of vertical motion effects on soil liquefaction. Geotechnique 2004; 54(10): 671-676.

[21] Zienkiewicz OC, Chang CT, Bettess P. Drained, undrained, consolidating and dynamic behaviour assumptions in soils. Geotechnique 1980; 30(4): 385-395.

[22] Ulker MBC, Rahman MS. Response of saturated and nearly saturated porous media: Different formulations and their applicability. Int J Numer Anal Met 2009; 33(5): 633-664.

[23] Verruij A. Elastic storage of aquifers. In: Flow through porous Media, (ed, De Wiest RJM), Academic Press, New York. 1969; 331-376.

[24] Madsen OS. Wave-induced pore pressures and effective stresses in a porous bed. Géotechnique, 1978; 28(4): 377-393.

[25] Biot MA. Mechanics of deformation and acoustic propagation in porous media. J Appl Phys 1962; 33(4): 1482-1498.

[26] Matsumoto H, Kaneda Y. Some features of bottom pressure records at the 2011 Tohoku earthquake-Interpretation of the far-field DONET data. Proceedings of the 11th Society of Exploration Geophysicists of Japan International Symposium, Yokohama, Japan, 2013; 493-496.

[27] Filloux JH. Tsunami record on the open ocean floor, Geophys Res Lett 1982; 9(1): 25-28.

[28] Okusa S. Wave-induced stresses in unsaturated submarine sediment. Geotechnique 1985; 35(4): 517-532.

[29] Lin M, Jeng DS. Comparison of existing poroelastic models for wave damping in a porous seabed. Ocean Eng 2003; 30(11): 1335-1352.

[30] Yang J, Sato T. Interpretation of seismic vertical amplification observed at an array site. Bull Seismol Soc Am 2000; 90(2): 275-285.

[31] Anderson AL, Bryant WR. Gassy sediment occurrence and properties: Northern Gulf of Mexico. Geo-Mar Lett 1990, 10(4): 209-220. 
Table 1 Comparison between wave-induced and vertical-earthquake induced liquefaction in

2 seabed

\begin{tabular}{ccc}
\hline & Ocean-waves & Earthquake \\
\hline Loading type & Oscillating pressure & Stochastic acceleration \\
Loading position & Seabed surface & Lower bedrock surface \\
Drainage condition & Partially drained & Approximately undrained \\
Duration & Few hours or longer & Few minutes or shorter \\
Location of liquefaction & Near seabed surface & Near seabed surface \\
Liquefaction type & Cumulative or instantaneous & Mostly instantaneous \\
\hline
\end{tabular}

3 


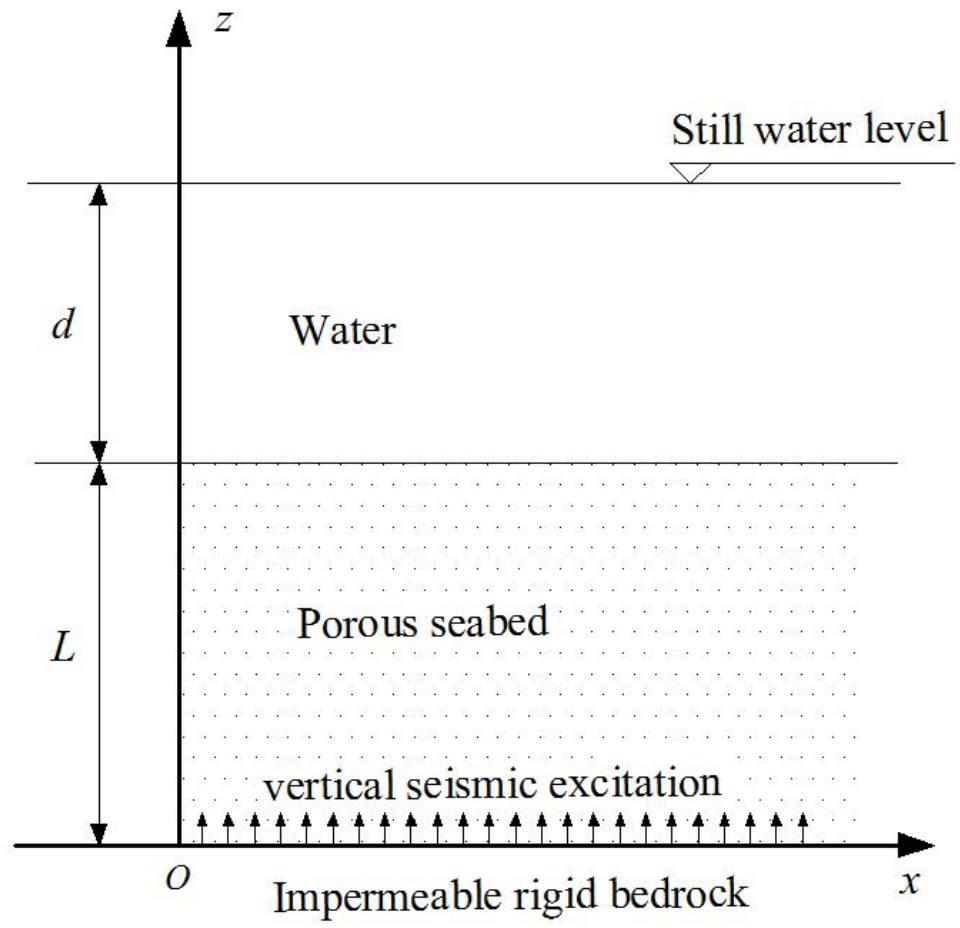

Fig. 1. Schematic diagram of the seismic problem. 


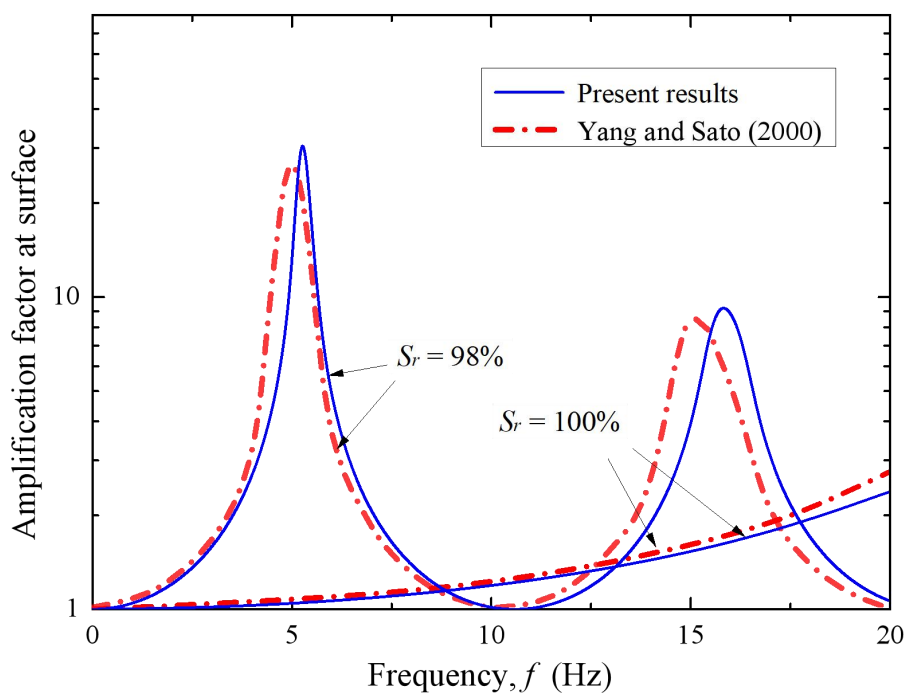

1

2 Fig. 2. Effects of frequency on the amplification factor of displacement at seabed surface when the 3 seawater is removed (i.e., $d=0 \mathrm{~m}$ ). 


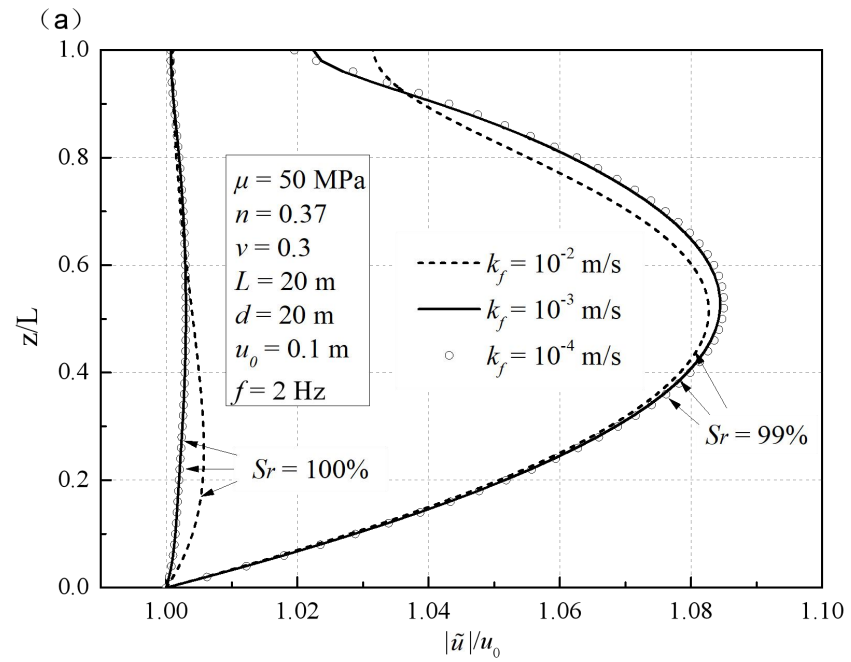

1

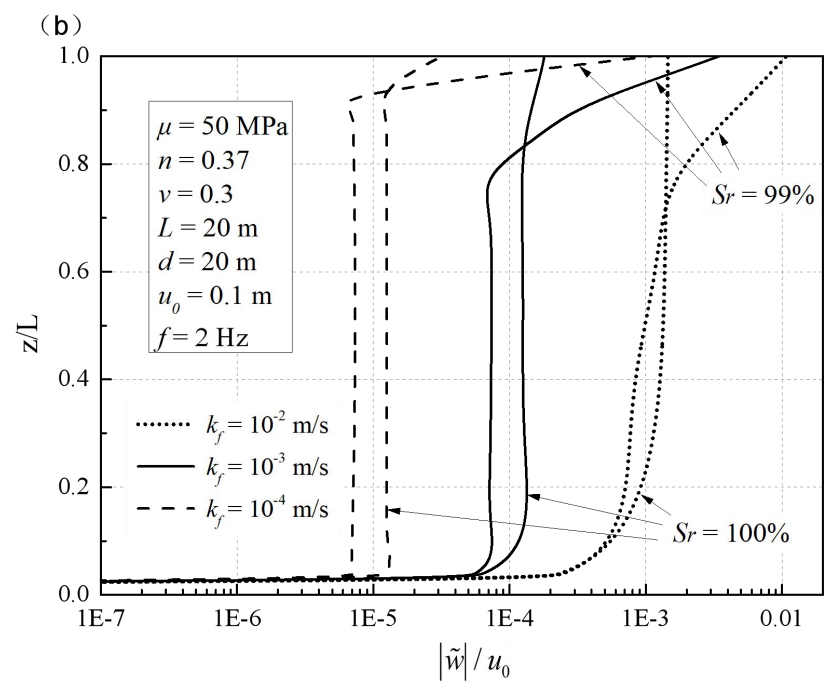

2

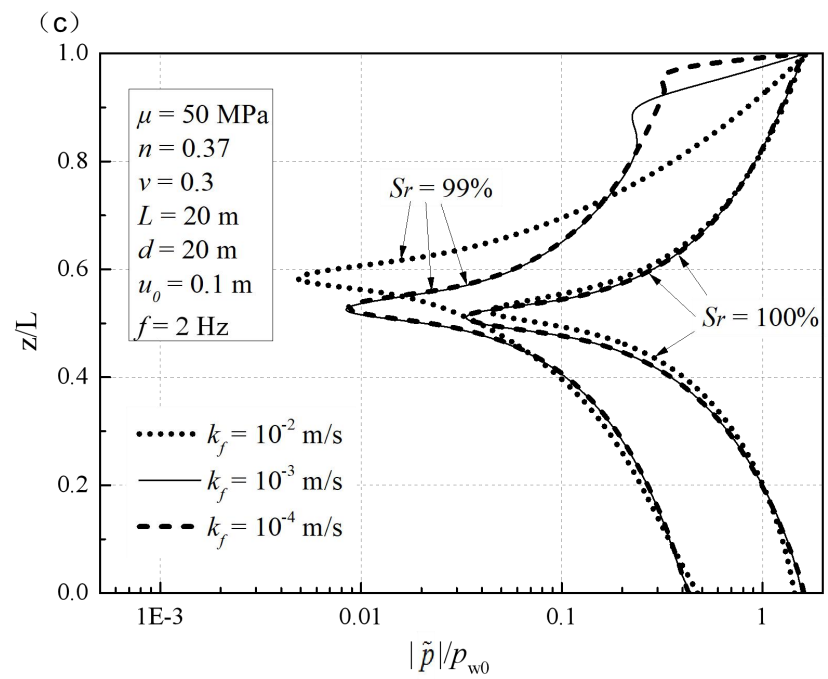

Fig. 3. Vertical distributions of (a) $|\tilde{u}| / u_{0}$, (b) $|\tilde{w}| / u_{0}$, and (c) $|\tilde{p}| / p_{w 0}$ versus the relative soil depth 


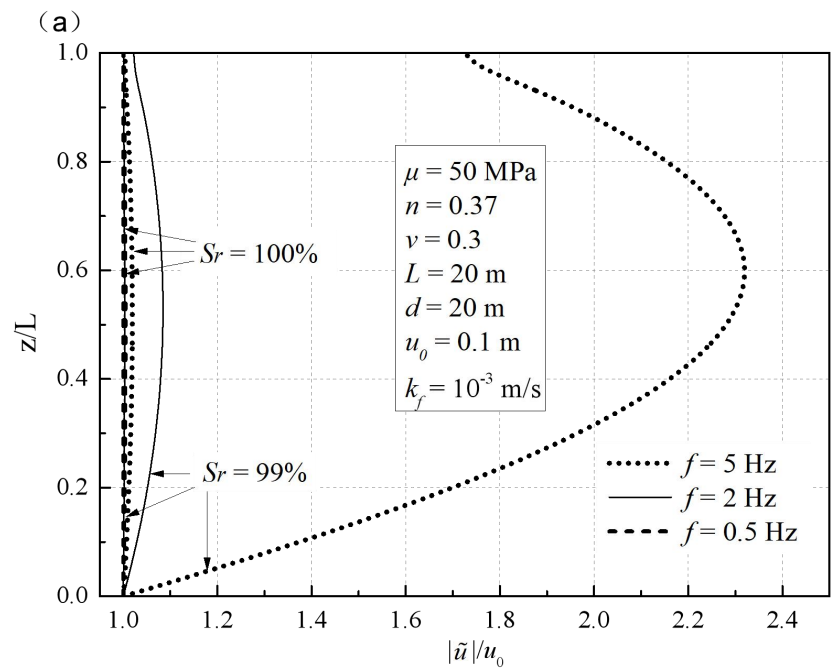

1

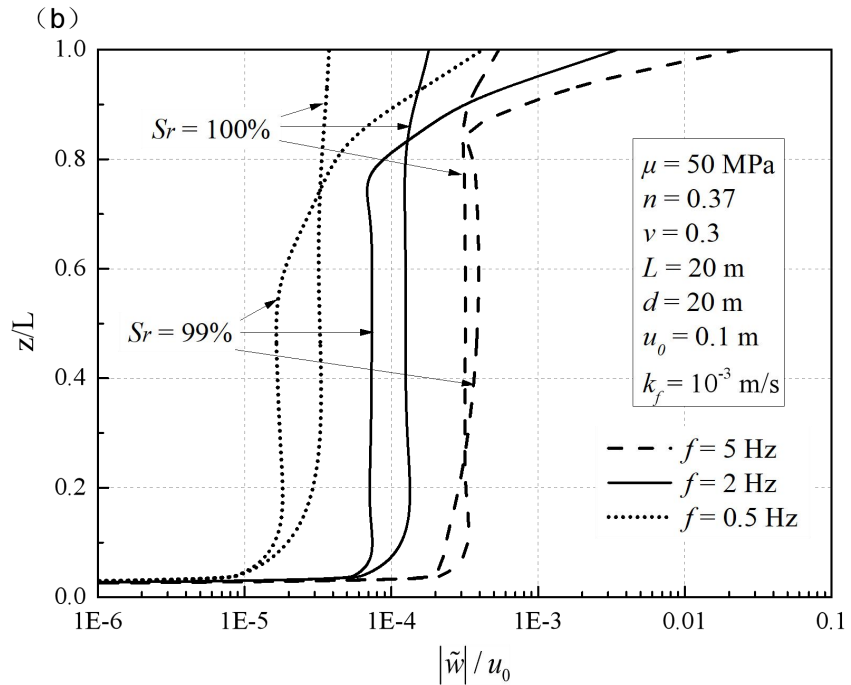

2

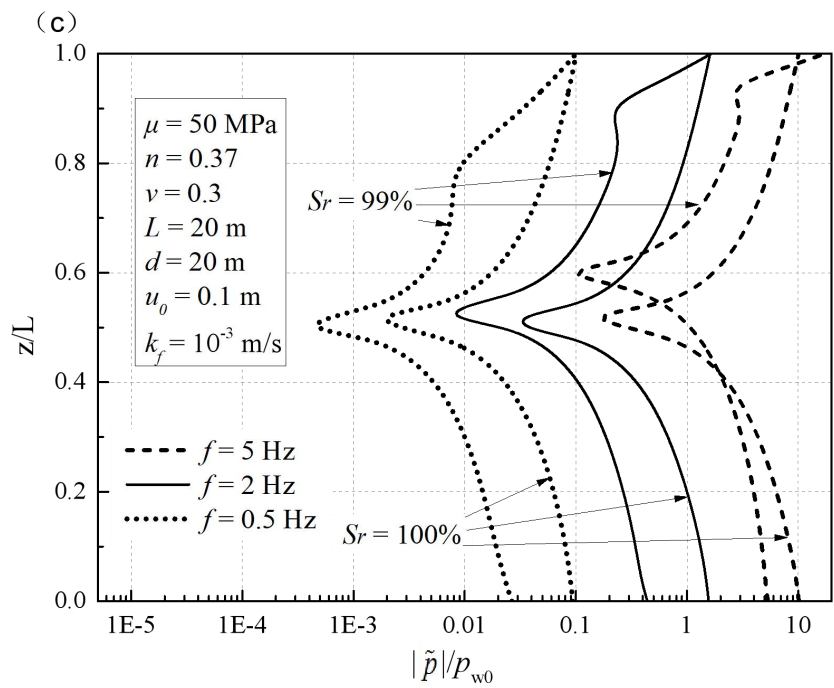

Fig. 4. Vertical distributions of (a) $|\tilde{u}| / u_{0}$, (b) $|\tilde{w}| / u_{0}$, and (c) $|\tilde{p}| / p_{w 0}$ versus the relative soil depth 5 $(z / L)$ for various excitation frequencies. 


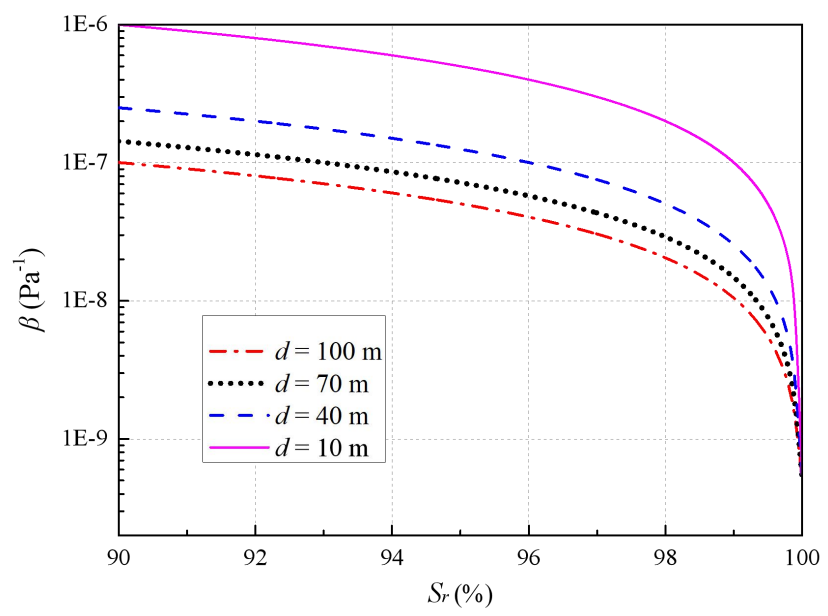

1

2 Fig. 5. Variation of the compressibility of pore fluid $\beta$ with saturation degree $S_{r}$ for different water 3 depths. 


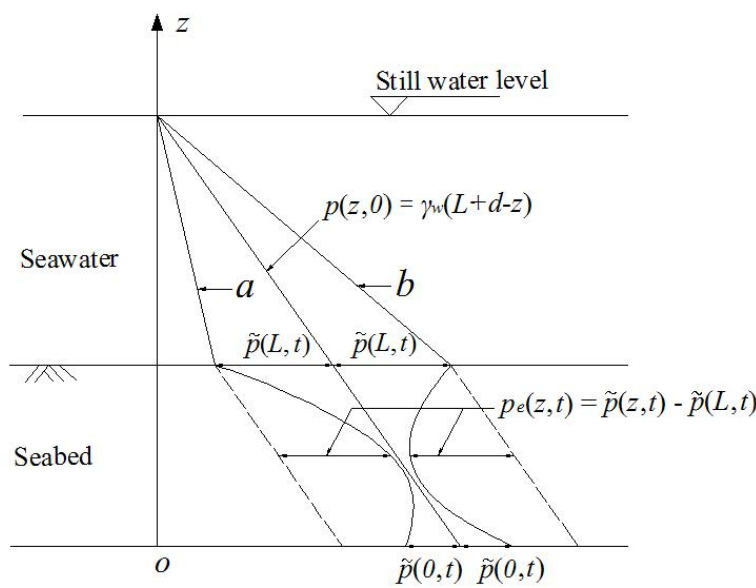

(a)

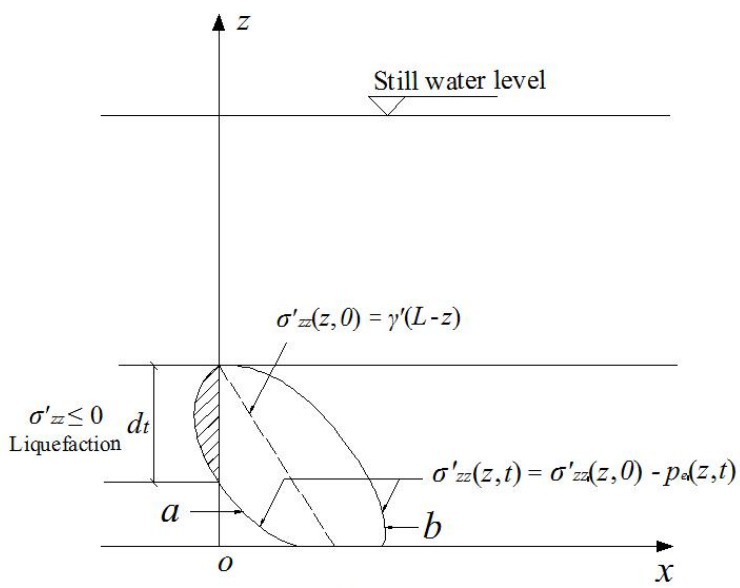

(b)

2 Fig. 6. Concept of excess pore pressure and momentary liquefaction for vertical seismic excitation:

3

(a) distribution of (pore) water pressure; (b) distribution of effective vertical stress.

4

5

6

7

8

9 


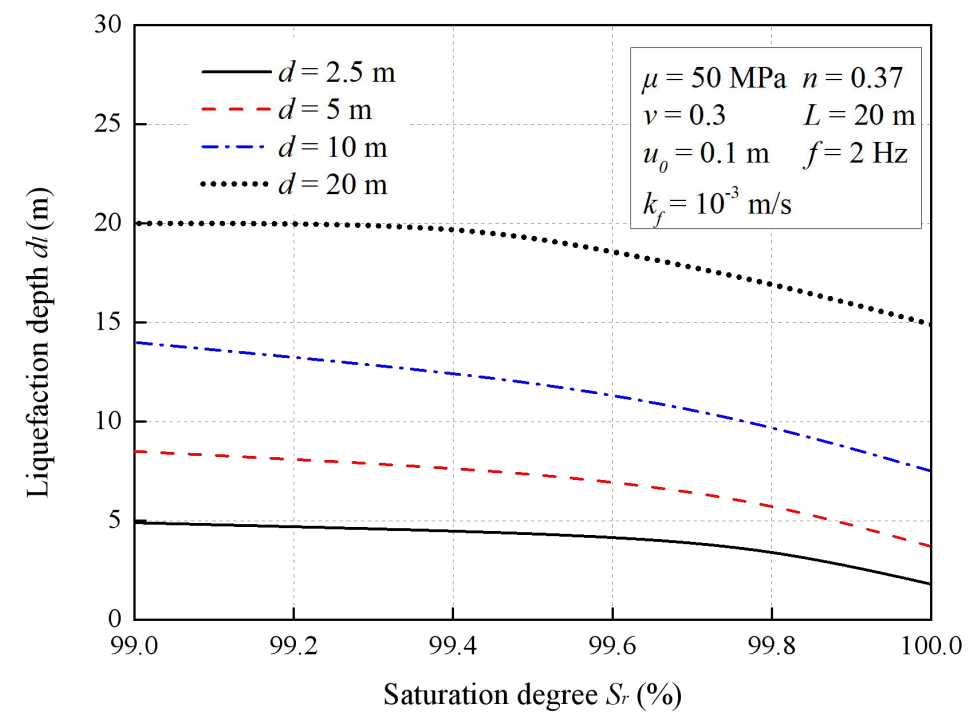

Fig. 7. Variation of liquefaction depth $d_{l}$ with saturation degree $S_{r}$ for different water depths.

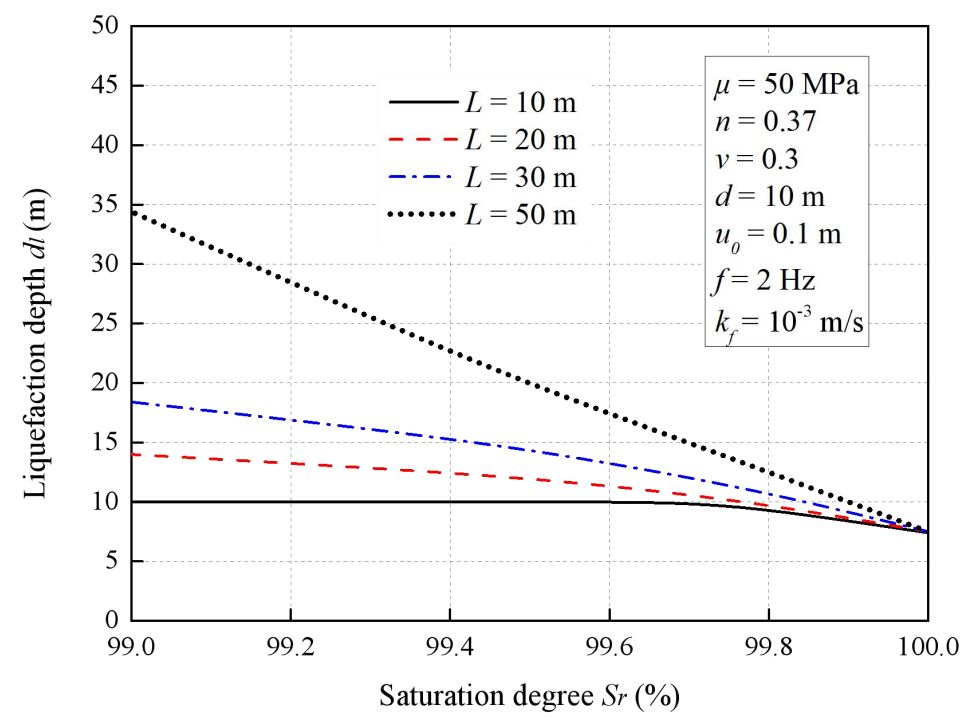

3

$4 \quad$ Fig. 8. Variation of liquefaction depth $d_{l}$ with saturation degree $S_{r}$ for different seabed thicknesses. 


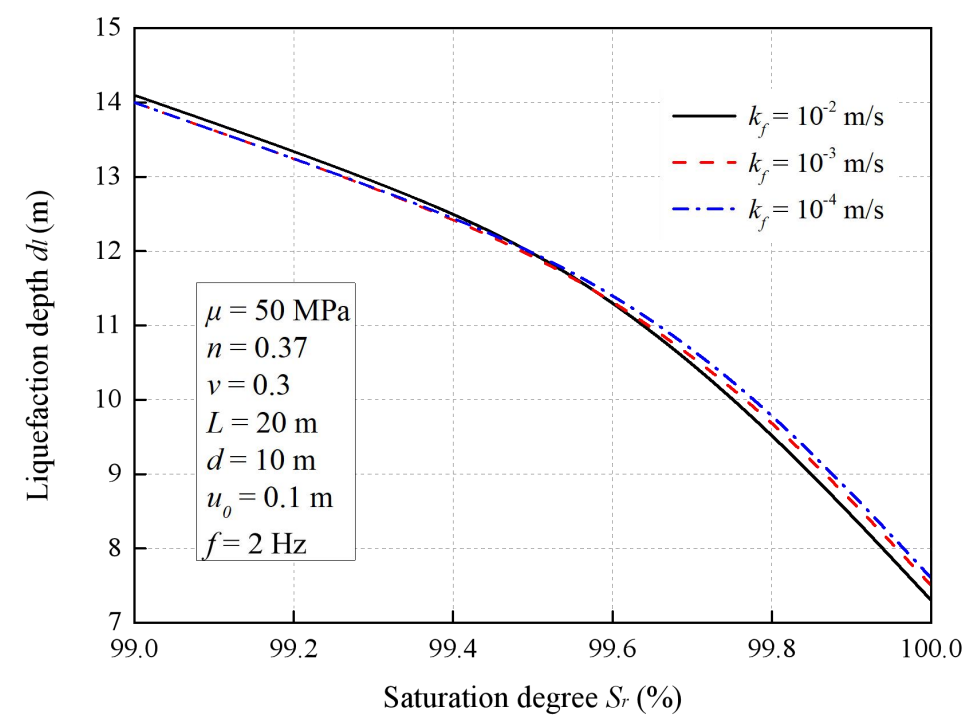

2 Fig. 9. Variation of liquefaction depth $d_{l}$ with saturation degree $S_{r}$ for different soil permeabilities. 3

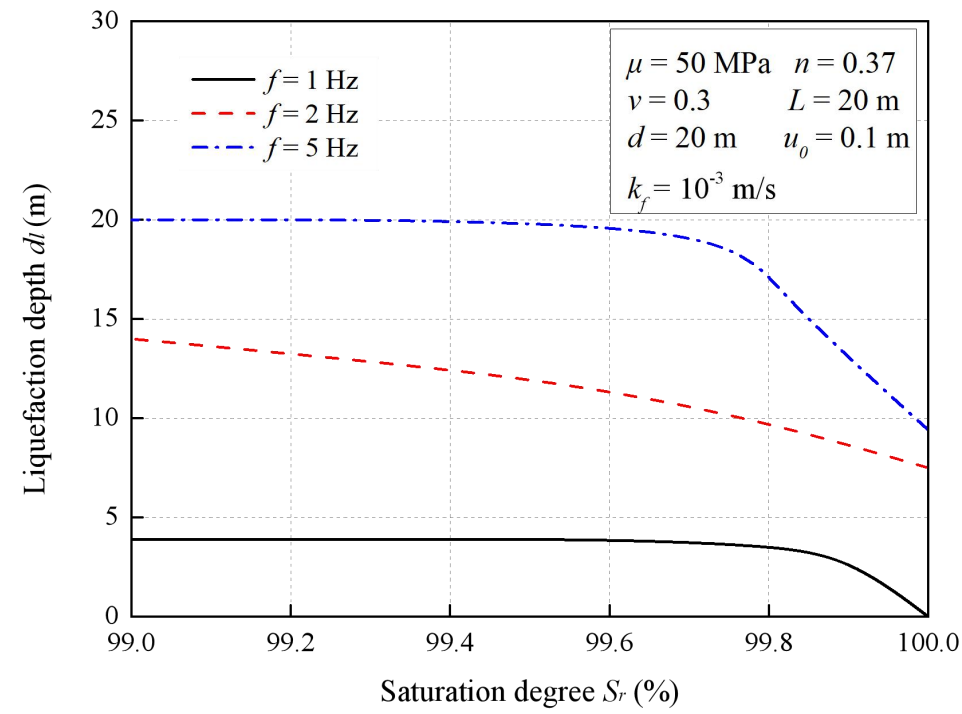

4

Fig. 10. Variation of liquefaction depth $d_{l}$ with saturation degree $S_{r}$ for different earthquake 6 frequencies. 


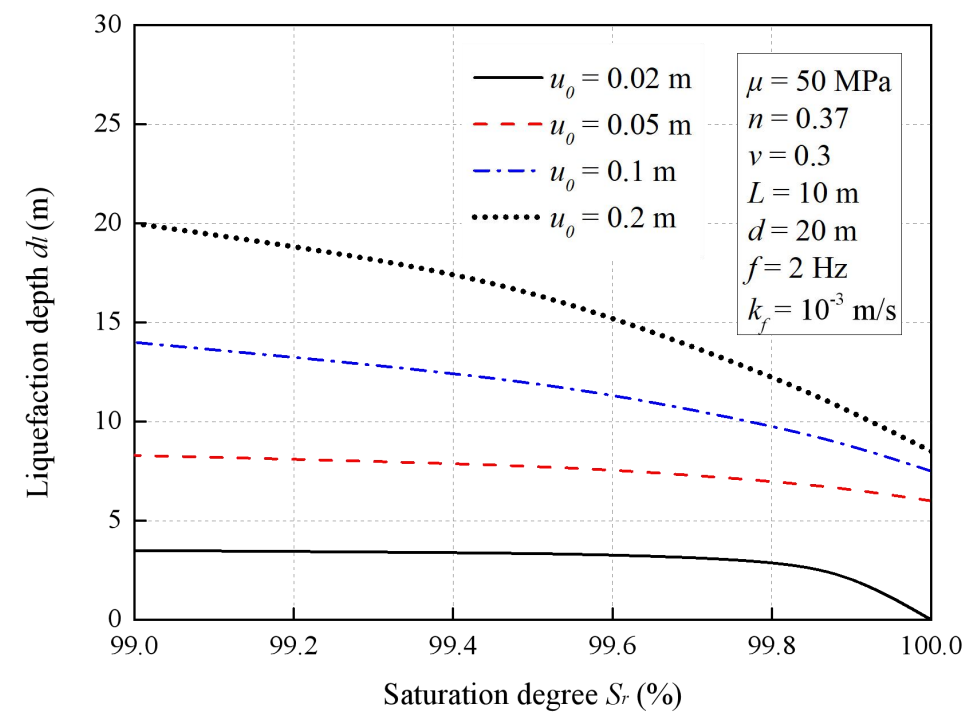

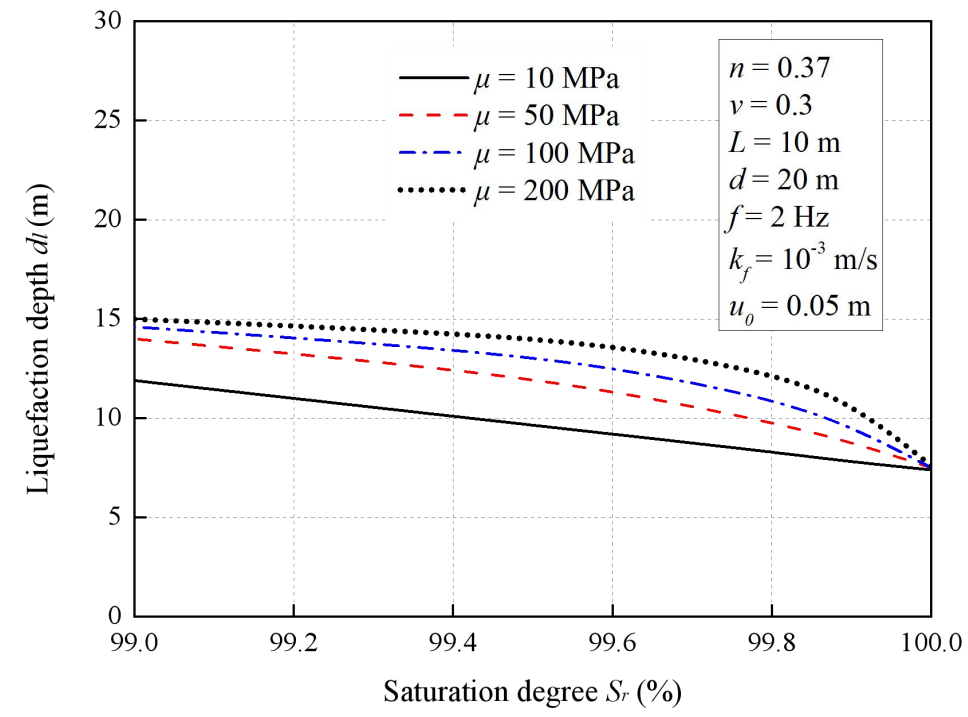

Fig. 11. Variation of liquefaction depth $d_{l}$ with saturation degree $S_{r}$ for different excitation displacement amplitudes.

Fig. 12. Variation of liquefaction depth $d_{l}$ with saturation degree $S_{r}$ for different shear moduli. 